\title{
The In Vitro and In Vivo Effects of Hypoxis hemerocallidea on Indinavir Pharmacokinetics: Modulation of Efflux
}

Authors

Kaylee Havenga ${ }^{1}$, Efrem Abay ${ }^{2}$, Lubbe Wiesner ${ }^{2}$, Alvaro Viljoen ${ }^{3,4}$, Dewald Steyn ${ }^{1}$, Josias Hamman ${ }^{1}$

Affiliations

1 Centre of Excellence for Pharmaceutical Sciences, Faculty of Health Sciences, North-West University, Potchefstroom, South Africa

2 Division of Clinical Pharmacology, Department of Medicine, University of Cape Town, Observatory, South Africa

3 Department of Pharmaceutical Sciences, Tshwane University of Technology, Pretoria, South Africa

4 SAMRC Herbal Drugs Research Center, Tshwane University of Technology, Pretoria, South Africa

\section{Key words}

Hypoxis hemerocallidea, Hypoxidaceae, herb-drug pharmacokinetic interactions, HIV, indinavir, traditional herbal medicines, efflux

$\begin{array}{ll}\text { received } & \text { January 26, } 2018 \\ \text { revised } & \text { April 2, 2018 } \\ \text { accepted } & \text { April 9, } 2018\end{array}$

\section{Bibliography}

DOI https://doi.org/10.1055/a-0607-2743

Published online April 19, 2018 | Planta Med 2018; 84: 895901 @ Georg Thieme Verlag KG Stuttgart · New York | ISSN 0032-0943

\section{Correspondence}

Prof Josias Hamman, PhD

Centre of Excellence for Pharmaceutical Sciences, Faculty of Health Sciences, North-West University

Private Bag X6001, Potchefstroom 2520, South Africa

Phone: + 27182994035 , Fax: + 27182992248

sias.hamman@nwu.ac.za $\circledast \begin{aligned} & \text { Supporting information available online at } \\ & \text { http://www.thieme-connect.de/products }\end{aligned}$

\section{ABSTRACT}

Hypoxis hemerocallidea (African potato) is a popular medicinal plant that has been used traditionally for the treatment of various disorders. Some HIV/AIDS patients use this traditional medicine together with their antiretroviral therapy. This study aimed to determine the impact of selected $H$. hemerocallidea materials (i.e., a commercial product, an aqueous extract, and biomass reference plant material) on the bidirectional permeability of indinavir across Caco- 2 cell monolayers as well as the bioavailability of indinavir during an acute, single administration study in Sprague-Dawley rats. All of the selected $H$. hemerocallidea test materials demonstrated inhibition effects on indinavir efflux across Caco- 2 cell monolayers, albeit to different extents. An increase in the bioavailability of indinavir was obtained in vivo when administered concomitantly with the $H$. hemerocallidea materials, albeit not statistically significantly. The change in bioavailability directly correlated with the in vitro permeability results. It can therefore be concluded that the change in permeability and bioavailability of indinavir was caused by efflux inhibition and this effect was dependent on the type of $H$. hemerocallidea material investigated, which was found to be in the following order: commercial product > aqueous extract > reference plant material. The clinical significance of the combined effect of efflux and metabolism inhibition by $\mathrm{H}$. hemerocallidea should be determined in another in vivo model that expresses the cytochrome P450 3A4 enzyme.

\section{Introduction}

Contradicting utilisation rates of traditional medicines are reported in the scientific literature for different countries around the globe. For example, it is frequently stated that $80 \%$ of the population of developing countries, especially sub-Saharan Africa, use traditional medicines [1-4], which is based on data obtained in 1983 [5]. A more recent survey done in six middle-income countries (China, Ghana, India, Mexico, Russia, and South Africa) as part of a World Health Organization (WHO) Study on Global AGEing and adult health (SAGE) found that the use of traditional medicine seems to be substantially lower (<3\%) [5]. Although traditional medicine use in Africa has decreased according to recent surveys, it varies widely among countries and regions on this continent [6]. There still seems to be a relatively large demand for medicinal plant usage by rural people, as shown by a study conducted in the Amatola region of the Eastern Cape Province in South Africa [7]. In addition, a survey in the Southern Africa region (including Botswana, Lesotho, South Africa, and Swaziland) found that $33.5 \%$ of participants indicated that people living with HIV/ AIDS use complementary treatments, which include traditional medicines, to help manage their symptoms [8]. Another relatively 

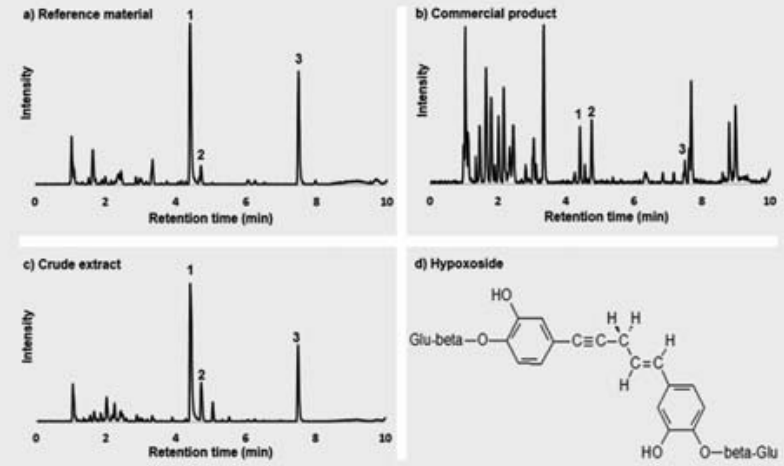

- Fig. 1 Chromatograms (TIC) of H. hemerocallidea materials: a reference plant material, b commercial product, $\mathrm{c}$ aqueous crude extract, and $\mathbf{d}$ chemical structure of hypoxoside [24]. Peak 1 = hypoxoside, peak 2 = dehydroxyhypoxoside, peak 3 = geraniol glycoside.

recent survey in the eThekwini Metropolitan area of the KwaZulu Natal Province in South Africa showed that more than $65.0 \%$ of the participants reported use of traditional medicines before the diagnosis of HIV and $77.6 \%$ reported traditional medicine use after their HIV diagnosis, while $4.98 \%$ of the patients used traditional medicines concurrently with their antiretroviral medicines during the study period [9].

Use of herbal products in conjunction with conventional medicines may lead to herb-drug pharmacokinetic or pharmacodynamic interactions [10-12]. Pharmacokinetic interactions may occur due to changes in the absorption, distribution, metabolism, and/or elimination (ADME) of a drug as a result of coadministration with an herbal product $[13,14]$. Mechanisms of action by which herb-drug pharmacokinetic interactions usually take place include modulation of intestinal active efflux transporters, such as P-glycoprotein (P-gp), as well as modulation of metabolising enzymes, specifically the cytochrome P450 (CYP450) super family [15]. These pharmacokinetic interactions may lead to increased or decreased bioavailability of the coadministered drug. Consequences of these bioavailability changes may either be adverse effects and even drug toxicity due to increased drug plasma levels or lack of pharmacological responses and treatment failure due to decreased drug plasma levels [16].

Hypoxis hemerocallidea Fisch., C. A.Mey. \& Avé-Lall. (Hypoxidaceae) is a popular traditional medicinal plant that is characterised by star-shaped flowers, which are bright yellow in colour, and by strap-like leaves [17]. This plant has a potato shaped tuberous rootstock (i.e., the corm), which is referred to as the "African potato". These corms are washed and chopped and the decoction is administered orally after boiling [1]. H. hemerocallidea extract, which contains phytosterols as well as hypoxoside and its active analogue rooperol, has been used for the treatment of certain types of cancers, heart failures, nervous disorders, immune-related illnesses, and urinary tract infections [18], and has also been used for the treatment of benign prostate hyperplasia as an antiinflammatory agent, antioxidant, anticonvulsant, and as an anti-
Table 1 Quantity of hypoxoside in each of the selected $H$. hemerocallidea materials.

\begin{tabular}{|l|c|}
\hline Test material & Hypoxoside $\mathbf{( m g / g )}$ \\
\hline Reference dried plant material & 13.3 \\
\hline Commercial product & 0.6 \\
\hline Aqueous extract & 151.7 \\
\hline
\end{tabular}

diabetic agent [19]. In vitro studies have suggested the possibility that $H$. hemerocallidea can cause pharmacokinetic interactions with drugs by means of inhibiting CYP450 enzymes as well as by modulation of efflux transporters [20]. Pharmacokinetic interactions were also observed between African potato decoctions and efavirenz in human volunteers. However, efavirenz is only a substrate for CYP450 enzymes and is not a substrate for efflux transporters such as P-gp [21]. Due to the interplay between P-gp efflux and CYP450-related metabolism, these two processes should ideally be considered together in terms of pharmacokinetic interactions [22,23]. This study was specifically conducted to identify pharmacokinetic interactions between $H$. hemerocallidea materials and an antiretroviral drug (i.e., indinavir) based on efflux modulation, since indinavir is a substrate for the efflux transporter P-gp.

\section{Results and Discussion}

The LC/MS chromatograms (chemical fingerprinting) of the $H$. hemerocallidea materials are shown in $>$ Fig. $\mathbf{1}$, while the quantities of hypoxoside in each of the selected $H$. hemerocallidea test materials are shown in $>$ Table $\mathbf{1 .}$

Chromatographic analysis revealed that all three of the selected $H$. hemerocallidea materials contained the marker molecule hypoxoside, albeit in different quantities. The aqueous extract of the corms contained a higher quantity of hypoxoside compared to that of the reference plant material and commercial product. The relatively low hypoxoside content of the commercial product can possibly be explained by the formulation composition, which caused a dilution effect due to other excipients in the dosage form as well as possible degradation of this phytochemical during manufacture of the product and/or storage of the raw materials.

The apparent permeability coefficient $\left(\mathrm{P}_{\text {app }}\right)$ values for indinavir in both directions across the Caco-2 cell monolayers in the presence of each selected $H$. hemerocallidea material as well as the control groups are shown in $>$ Fig. 2.

- Table 2 presents the efflux ratio (ER) values calculated from the bidirectional transport of indinavir in combination with the $H$. hemerocallidea materials compared to the control groups.

Verapamil, a known P-gp inhibitor, demonstrated an increased uptake of indinavir in the apical-to-basolateral (AP-BL) direction compared to that of the negative control group (i.e., indinavir alone), which can be explained by an inhibition of efflux. Inhibition of efflux was confirmed by a decreased transport in the basolateral-to-apical (BL-AP) direction of indinavir as well as the ER value when compared to that of the negative control group. The Caco- 


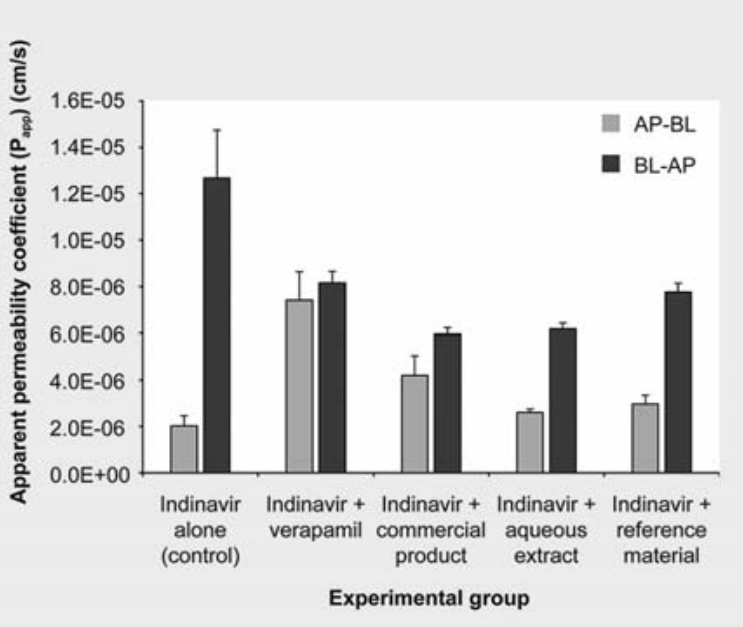

- Fig. 2 Bidirectional $P_{\text {app }}$ values calculated from indinavir transport across Caco-2 cell monolayers in combination with the selected $\mathrm{H}$. hemerocallidea materials $(500 \mu \mathrm{g} / \mathrm{mL})$ as well as the negative control group $(200 \mu \mathrm{M}$, indinavir alone) and positive control group (indinavir with verapamil $(100 \mu \mathrm{M})$. AP-BL = apical-to-basolateral direction, $\mathrm{BL}-\mathrm{AP}=$ basolateral-to-apical direction, $\mathrm{n}=3$, error bars indicate standard deviation.

2 cell line therefore proved to be an acceptable model for testing efflux modulation of indinavir. Similarly, the transport of indinavir was increased in the AP-BL direction by all three selected $\mathrm{H}$. hemerocallidea materials investigated in this study compared to that of the control group, while indinavir transport was decreased in the BL-AP direction compared to that of the control group. This clearly showed that active efflux transport of indinavir was inhibited by the selected $H$. hemerocallidea materials, albeit not to the same extent of efflux inhibition observed for verapamil.

The effect on the efflux of indinavir in the Caco-2 model depended on the type of $\mathrm{H}$. hemerocallidea material, which contained different concentrations of hypoxoside. However, the efflux inhibition did not correlate directly with the hypoxoside concentration and therefore other phytoconstituents also contributed to this effect. From the in vitro transport results obtained in this study, it can be expected that coadministration of indinavir (as well as other antiretroviral drugs that are substrates for P-gp) with $H$. hemerocallidea extracts and plant materials will most probably lead to enhanced blood plasma levels of indinavir.

Indinavir is a known substrate for CYP3A4 [25], and $\mathrm{H}$. hemerocallidea extracts have been shown to inhibit CYP3A4 enzyme activity within in vitro models [26], however, this study only focussed on the effect of the modulation of efflux on indinavir permeation and bioavailability by different $\mathrm{H}$. hemerocallidea materials.

Validation of the LC/MS/MS method provided an accuracy between 94.0 and $106.9 \%$, precision (coefficient of variance or CV) below $7.2 \%$, and linearity (correlation coefficient or $R^{2}$ ) of 0.999 for indinavir in the quality control samples. The plasma concentration time curves for indinavir alone and in the presence of the selected $H$. hemerocallidea materials administered after a single administration (acute study) are shown in $\boldsymbol{\vee}$ Fig. $\mathbf{3}$, while the mean
- Table 2 ER values calculated from the bidirectional transport of indinavir across Caco-2 cell monolayers in the absence and presence of the selected $H$. hemerocallidea materials.

\begin{tabular}{|l|l|}
\hline Experimental group & ER \pm SD* \\
\hline Indinavir $(200 \mu \mathrm{M})$ alone (negative control) & $6.27 \pm 4.75$ \\
\hline $\begin{array}{l}\text { Indinavir }(200 \mu \mathrm{M}) \text { with verapamil }(100 \mu \mathrm{M}, \\
\text { positive control) }\end{array}$ & $1.10 \pm 0.40$ \\
\hline $\begin{array}{l}\text { Indinavir }(200 \mu \mathrm{M}) \text { with } \mathrm{H} \text {. hemerocallidea } \\
\text { commercial product }(500 \mu \mathrm{g} / \mathrm{mL})\end{array}$ & $1.42 \pm 0.33$ \\
\hline $\begin{array}{l}\text { Indinavir }(200 \mu \mathrm{M}) \text { with } \mathrm{H} \text {. hemerocallidea } \\
\text { aqueous extract }(500 \mu \mathrm{gL})\end{array}$ & $2.37 \pm 1.70$ \\
\hline $\begin{array}{l}\text { Indinavir }(200 \mu \mathrm{M}) \text { with } \mathrm{H} \text {. hemerocallidea } \\
\text { reference material }(500 \mu \mathrm{g} / \mathrm{mL})\end{array}$ & $2.61 \pm 1.02$ \\
\hline *SD = standard deviation & \\
\hline
\end{tabular}

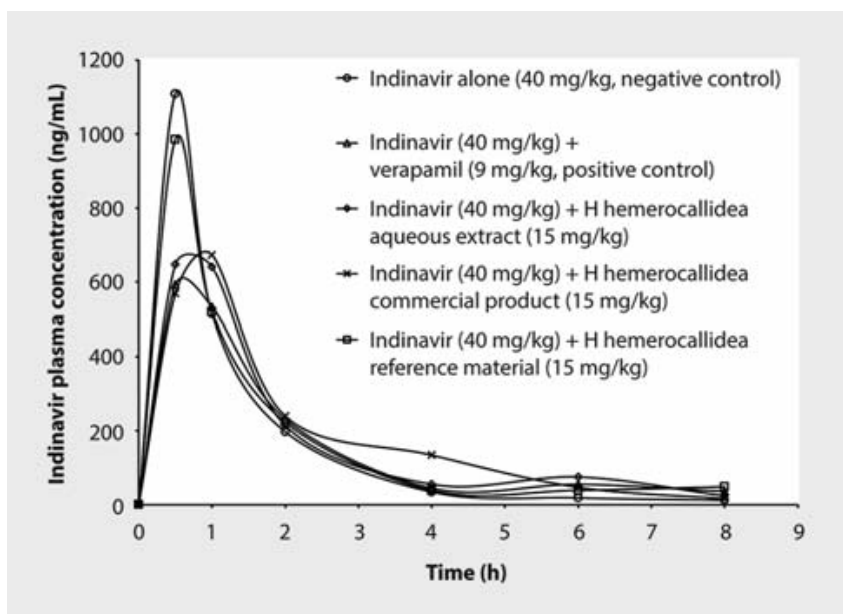

- Fig. 3 Plasma concentration time curves for indinavir alone ( $40 \mathrm{mg} / \mathrm{kg}$, negative control) and in the presence of selected H. hemerocallidea materials $(15 \mathrm{mg} / \mathrm{kg}$ ) as well as verapamil $(9 \mathrm{mg} /$ $\mathrm{kg}$, positive control); $\mathrm{n}=5$, error bars are omitted for reasons of clarity.

plasma concentrations at each time point with standard deviations are given in Table 1S, Supporting Information.

The bioavailability parameters for indinavir alone and in the presence of the selected $H$. hemerocallidea test materials after a single administration (acute study) are listed in $>$ Table 3 . These bioavailability parameters include the area under the curve extrapolated to infinity $\left(\mathrm{AUC}_{0-\infty}\right)$ as well as maximum plasma concentration $\left(C_{\max }\right)$ and relative bioavailability $\left(F_{\text {rel }}\right)$ values.

From $>$ Table 3 it is clear that coadministration of the selected $H$. hemerocallidea test materials increased the bioavailability $\left(A \cup C_{0-\infty}\right)$ of indinavir in rats compared to the negative control group (indinavir alone), albeit not statistically significantly $(p \geq 0.05)$. In accordance with the in vitro transport results, where the $H$. hemerocallidea commercial product increased the AP-BL transport, the highest of all three of the selected materials, it also exhibited the highest enhancement of indinavir bioavailability 
- Table 3 Biopharmaceutical parameters for indinavir administrated to rats in the absence and presence of the selected $H$. hemerocallidea materials.

\begin{tabular}{|c|c|c|c|}
\hline Experimental group & $\mathrm{AUC}_{0-\infty}\left(\mathrm{ng}^{*} \mathrm{~min} / \mathrm{mL}\right)^{\#}$ & $C_{\max }(\mathrm{ng} / \mathrm{mL})^{\#}$ & $F_{\text {rel }}$ \\
\hline Indinavir (40 mg/kg) alone (negative control) & $1371.0 \pm 389.8$ & $1108.6 \pm 484.3$ & 1.00 \\
\hline Indinavir (40 mg/kg) with verapamil (9 mg/kg, positive control) & $1501.3 \pm 462.2$ & $644.1 \pm 488.8$ & 1.10 \\
\hline Indinavir (40 mg/kg) with H. hemerocallidea aqueous extract ( $15 \mathrm{mg} / \mathrm{kg})$ & $1458.3 \pm 512.6$ & $813.6 \pm 563.5$ & 1.06 \\
\hline Indinavir (40 mg/kg) with $H$. hemerocallidea commercial product ( $15 \mathrm{mg} / \mathrm{kg}$ ) & $1564.4 \pm 638.2$ & $928.0 \pm 493.0$ & 1.14 \\
\hline Indinavir (40 mg/kg) with $\mathrm{H}$. hemerocallidea reference plant material $(15 \mathrm{mg} / \mathrm{kg})$ & $1456.6 \pm 316.3$ & $1022.0 \pm 412.0$ & 1.06 \\
\hline
\end{tabular}

$\mathrm{AUC}_{0-\infty}=$ area under the curve, $\mathrm{C}_{\max }=$ maximum plasma concentration, $\mathrm{F}_{\mathrm{rel}}=$ relative bioavailability. ${ }^{\#}$ Average \pm standard deviation; $\mathrm{n}=5$

$\left(A \cup C_{0-\infty}\right)$ in the rats during the acute study. Overall, the bioavailability results from the acute study correlated well with the in vitro transport results in terms of efflux inhibition as expressed by the efflux ratio results (i.e., $E R=1.42$ for the commercial product compared to $E R=2.37$ and $E R=2.61$ for the aqueous extract and reference material, respectively).

The pharmacokinetic effects of $H$. hemerocallidea materials on indinavir bioavailability in this study can therefore be attributed to the inhibition of efflux, and the extent of inhibition was dependent on the type of $\mathrm{H}$. hemerocallidea material. As mentioned before, modulation of metabolism can also play a role in interactions between $\mathrm{H}$. hemerocallidea and indinavir, but this was not investigated in this study. The rat serves as a model for certain cytochrome P450 enzymes (e.g., CYP1A2 and CYP2E1), but not for CYP3A4 [27], which is the most prevalent enzyme for indinavir metabolism in humans.

It can be deduced from this study that concurrent use of $H$. hemerocallidea poducts or extracts by people living with HIV/ AIDS that are on antiviral treatment (i.e., indinavir) can cause pharmacokinetic interactions that can lead to increased blood levels of indinavir. However, in order to determine if this effect is clinically significant, a follow-up study is needed in an animal model that expresses the CYP3A4 enzyme (e.g., pig model) in order to determine the combined effect of efflux inhibition and metabolism inhibition on the bioavailability of indinavir.

\section{Materials and Methods}

\section{Plant materials, chemical compounds, cell line, and growth media}

The dried $H$. hemerocallidea bulb material (i.e., biomass reference material) was purchased from ChromaDex (sample HHC 001 stored at the Department of Pharmaceutics, North-West University), which was provided with a certificate of analysis as authenticated with high-performance thin-layer chromatography. The solid oral commercial product (Hypoxis VegeCaps, batch nr. HYO001, sample HHC 002 stored at the Department of Pharmaceutics, North-West University) containing $300 \mathrm{mg} \mathrm{H}$. hemerocallidea plant tuber material (total mass of capsule content was $403.74 \mathrm{mg}$ ) was purchased from a local health shop. The aqueous extract was prepared from $\mathrm{H}$. hemerocallidea corms (voucher $\mathrm{HH}$ 064 retained at the Department of Pharmaceutical Sciences,
Tshwane University of Technology) by weighing approximately $5 \mathrm{~g}$ of dried $\mathrm{H}$. hemerocallidea corm material accurately in a 50$\mathrm{mL}$ Erlenmeyer flask. A volume of $10 \mathrm{~mL}$ of deionized water was added and the mixture was sonicated at $45^{\circ} \mathrm{C}$ for $30 \mathrm{~min}$. After filtering the mixture through a filter paper (No. 4, Whatman), the filtrate was kept aside and the residue was returned to the flask. This process was repeated twice, where afterwards the filtrates were combined and the residue discarded. The water filtrate was frozen and subsequently freeze-dried overnight, and the extract was stored in a desiccator. All three of the $H$. hemerocallidea materials were chemically characterised by means of liquid chromatography linked to mass spectrometry (LC/MS) as described below in the next section.

Crixivan capsules (MSD, batch nr. w076460) containing $400 \mathrm{mg}$ indinavir per capsule (total mass of capsule content was $658 \mathrm{mg}$ ) was purchased from a local pharmacy (sample HHC 003 stored at the Department of Pharmaceutics, North-West University). Verapamil was donated by Sandoz (South Africa) with a certificate of analysis stating a purity of $99.3 \%$ (sample HHC 004 stored at the Department of Pharmaceutics, North-West University).

The Caco-2 cell line was obtained from the European Collection of Cell Cultures (ECACC). The high-glucose DMEM, penicillin, and streptomycin were supplied by Separations. Whitehead Scientific supplied the nonessential amino acids, L-glutamine, and TrypsinVersene mixture, while foetal bovine serum and amphotericin B were obtained from The Scientific Group.

\section{Chemical characterisation of the Hypoxis hemero- callidea materials by means of LC/MS}

Chemical fingerprinting as well as the determination of the quantity of hypoxoside in each of the three selected $H$. hemerocallidea materials was done by means of LC/MS. The chromatographic analysis was performed on a Waters Acquity UHPLC system with a photo diode array (PDA) detector (Waters). UHPLC separation was attained on an Acquity BEH $\mathrm{C}_{18}$ column $(150 \mathrm{~mm} \times 2.1 \mathrm{~mm}$, $1.7 \mu \mathrm{m}$ particle size; Waters), which was maintained at $40^{\circ} \mathrm{C}$ during analysis. The mobile phase consisted of $0.1 \% \mathrm{v} / \mathrm{v}$ formic acid in water (solvent A) and acetonitrile (solvent B) with a flow rate of $0.3 \mathrm{~mL} / \mathrm{min}$. A gradient elution was employed as follows: the analysis started with a $85 \%$ A:15\% B mixture, which was changed to a mixture of $65 \% \mathrm{~A}: 35 \% \mathrm{~B}$ in $7 \mathrm{~min}$ and then to $50 \% \mathrm{~A}: 50 \% \mathrm{~B}$ in 1 min, which was maintained for 0.5 min after which it was changed back to the initial mixture in $0.5 \mathrm{~min}$. The total running 
time was $11 \mathrm{~min}$. The standard and samples were injected into the mobile phase with an injection volume of $1.0 \mu \mathrm{L}$ (full-loop injection). Mass spectrometry (MS) was operated in the negative ion electrospray mode. The desolvation gas was nitrogen $\left(\mathrm{N}_{2}\right)$, while the desolvation temperature was set to $350^{\circ} \mathrm{C}$ at a flow rate of $500 \mathrm{~L} / \mathrm{h}$ and the source temperature was set to $100^{\circ} \mathrm{C}$. The capillary and cone voltages were set to $2500 \mathrm{~V}$ and $45 \mathrm{~V}$, respectively. The analytical data were collected between 100 and $1000 \mathrm{~m} / \mathrm{z}$.

\section{Bidirectional in vitro permeability across Caco- 2 cell monolayers}

The Caco-2 cells were cultured in high-glucose DMEM supplemented with $10 \%$ foetal bovine serum, $1 \%$ nonessential amino acids (NEAA), 1\% penicillin/streptomycin, 1\% $2 \mathrm{mM}$ L-glutamine, and $1 \%$ amphotericin $B(250 \mu \mathrm{g} / \mathrm{mL})$. Culturing of the cells occurred at a temperature of $37^{\circ} \mathrm{C}$ with $5 \%$ carbon dioxide and $95 \%$ humidified air in a Galaxy 170R incubator (Eppendorf). The growth medium was exchanged every second day under sterile conditions in a laminar flow hood. The cells were examined by means of a light microscope (Nikon Eclipse TS100/TS100F, Nikon Instruments) prior to exchange of the growth medium. The percentage confluency was estimated and the absence of any contamination was ensured. Subculturing by means of trypsinisation took place once the cells reached a confluency of $50-60 \%$.

Caco-2 cells (passage 50) were seeded onto Transwell 6-well membrane filters (Corning Costar Corporation) with a surface area of $4.67 \mathrm{~cm}^{2}$ and a pore diameter of $0.4 \mu \mathrm{m}$. The cell suspension was obtained through trypsinisation by adding a Trypsin-versene mixture and then incubated for 5 min. After cell detachment, $6 \mathrm{~mL}$ of pre-warmed growth medium were added to the flask. The cell suspension was extensively agitated with a pipette to ensure complete cell detachment and deagglomeration in order to form a suspension consisting of single cells. This single cell suspension was then transferred to a $50-\mathrm{mL}$ tube. A Pasteur pipette was used to agitate the cell suspension to make sure that a homogenous cell distribution was present. A haemocytometer was used to count the cells in the suspension after Trypan blue was added. The average number of cells per square was calculated and this number was then multiplied with the dilution factor $\left(5 \times 10^{4}\right)$ in order to establish the total number of cells per $\mathrm{mL}$ in the cell suspension. The cell suspension was diluted to a concentration of 20000 cells per $\mathrm{mL}$, and a volume of $2.5 \mathrm{~mL}$ was pipetted into each apical chamber of the membrane filter plate wells. The growth medium was exchanged every second day and the cells were cultured for 21-24 days until intact epithelial monolayers were obtained.

The transepithelial electrical resistance (TEER) of each Caco-2 cell monolayer was measured with a Millcell ERS II meter (Millipore) prior to the commencement of the transport studies. Measurement of TEER is one method that is used to establish tight junction integrity of Caco- 2 cell monolayers and a value of $\geq 150 \Omega$ is considered sufficient [28]. In this study, a TEER reading of higher than $250 \Omega$ (equivalent to $1167.5 \Omega / \mathrm{cm}^{2}$ ) was required before commencement of the transport studies [29]. The TEER was measured again at the end of the study to ensure cell monolayer integrity was maintained during the transport study.
To prepare a 200- $\mu \mathrm{M}$ indinavir solution (negative control), the correct equivalent mass of a Crixivan capsule content (i.e., $2.02 \mathrm{mg}$ ) was weighed and added to $10 \mathrm{~mL}$ DMEM and stirred until dissolved. For the test solutions, a sufficient amount of each of the selected $H$. hemerocallidea materials was added to the indinavir solution to reach a concentration of $500 \mu \mathrm{g} / \mathrm{mL}$ for each of the $H$. hemerocallidea materials [30]. A 100- $\mu \mathrm{M}$ verapamil solution was prepared by dissolving $0.45 \mathrm{mg}$ verapamil into $5 \mathrm{~mL}$ in the indinavir solution. For the transport in the AP-BL direction, the growth medium was removed from the basolateral chamber and replaced with a volume of $2.5 \mathrm{~mL}$ preheated transport medium (DMEM) buffered with HEPES. The Transwell plate was then kept in the incubator for 30 min before the growth medium was removed from the apical chambers and replaced with $2.5 \mathrm{~mL}$ of the test solutions. Samples $(200 \mu \mathrm{L})$ were withdrawn from the basolateral chambers at time intervals of 20,40,60, 80, 100, and $120 \mathrm{~min}$, and were replaced with an equal volume of preheated transport buffer. Samples were analysed by a previously described HPLC analysis method [29] to determine the concentration of indinavir that appeared in the acceptor chamber over time.

For the transport in the BL-AP direction, the same method was used, except that the growth medium was removed from the basolateral chambers and replaced with $2.5 \mathrm{~mL}$ of each test solution. Samples $(200 \mu \mathrm{L})$ were withdrawn from the apical chambers at the time intervals of $20,40,60,80,100$, and 120 min and immediately replaced with an equal volume of preheated DMEM.

Indinavir alone $(200 \mu \mathrm{M})$ served as the negative control group, while indinavir in combination with $100 \mu \mathrm{M}$ verapamil, a known P-gp inhibitor, served as the positive control group. The test solutions consisting of the selected $H$. hemerocallidea materials $(500 \mu \mathrm{g} / \mathrm{mL})$ in combination with indinavir $(200 \mu \mathrm{M})$ formed the experimental groups. All transport experiments were conducted in triplicate.

The $P_{\text {app }}$ values for the transport of indinavir was calculated according to the following equation [29]:

$P_{\mathrm{app}}=\frac{\mathrm{dQ}}{\mathrm{dt}}\left(\frac{1}{\mathrm{~A} \cdot \mathrm{C}_{0} \cdot 60}\right)$

Where $P_{\text {app }}$ is the apparent permeability coefficient $(\mathrm{cm} / \mathrm{s}), \mathrm{dQ} / \mathrm{dt}$ is the permeability rate (amount permeated per minute), $A$ is the diffusion area of the membrane $\left(\mathrm{cm}^{2}\right)$, and $C_{0}$ is the initial concentration of the model drug.

The ER value indicates any asymmetry in the directional transport of indinavir in combination with the different $\mathrm{H}$. hemerocallidea materials. The ER value was calculated according to the following equation:

$E R=\frac{P_{\text {app }}(B-A)}{P_{\text {app }}(A-B)}$

Where $P_{\text {app }}(B-A)$ is the permeability coefficient for the permeation in the basolateral-to-apical direction and $P_{a p p}(A-B)$ is the permeability coefficient for the permeation in the apical-to-basolateral direction. 


\section{In vivo bioavailability studies}

The in vivo pharmacokinetic study in Sprague Dawley rats [obtained from South African Vaccine Producers (SAVP)] was approved by the Faculty of Health Sciences Animal Ethics Committee of the University of Cape Town, South Africa (reference number: 015/041, date of approval: 17/03/2016). All animal experiments were implemented and conducted according to national and international accepted principles and standards for humane handling of animals. A total of 25 male Sprague Dawley rats weighing 250-300 g was randomly selected and divided into 5 different groups as summarised in $>$ Fig. 4 .

The test solutions consisted of the selected $H$. hemerocallidea materials at a concentration of $15 \mathrm{mg} / \mathrm{kg}$ coadministered with indinavir at a concentration of $40 \mathrm{mg} / \mathrm{kg}$ (based on equivalent Crixivan capsule content), while indinavir $(40 \mathrm{mg} / \mathrm{kg}$, based on equivalent Crixivan capsule contents) was administered alone as the negative control group. The positive control for efflux inhibition consisted of indinavir $(40 \mathrm{mg} / \mathrm{kg})$ with verapamil $(9 \mathrm{mg} / \mathrm{kg})$ [31]. The test solutions were administered by means of oral gavage at a volume of $500 \mu \mathrm{L}$ per animal.

Blood samples $(200 \mu \mathrm{L})$ were collected from the tail veins of the animals at predetermined time intervals of $0,0.5,1,2,4,8$, and $24 \mathrm{~h}$ after administration of each experimental and control test solution. Sample tubes were sprayed with heparin beforehand, which served as an anticoagulant. The blood samples were then centrifuged for $8 \mathrm{~min}$ at $14000 \mathrm{rpm}$, after which the plasma was recovered from each blood sample. The plasma samples were kept at $-80^{\circ} \mathrm{C}$ until the indinavir analysis occurred.

A previously described LC/MS/MS method for the analysis of indinavir was used in order to analyse the plasma samples for indinavir concentration with slight modifications as outlined below [32].

Briefly, the liquid chromatography method entailed using a Kinetex F5 $(4.6 \times 100 \mathrm{~mm}, 2.6 \mu \mathrm{m})$ analytical column on an Agilent 1100 series HPLC. The mobile phase consisted of a mixture of $A$ and $B$ at $50: 50 \mathrm{v} / \mathrm{v}$, where mobile phase $A$ was $0.1 \%$ formic acid in water and $B$ was $0.1 \%$ formic acid in acetonitrile. The mobile phase was delivered at a constant flow rate of $500 \mu \mathrm{L} / \mathrm{min}$. The column was kept in a column compartment at $40^{\circ} \mathrm{C}$. An autosampler injected $10 \mu \mathrm{L}$ onto the HPLC column. The injection needle was rinsed with mobile phase before each injection for 30 s using the flush port wash station. The samples were cooled to $4^{\circ} \mathrm{C}$ while awaiting injection.

Detection of indinavir and the internal standard (indinavir- $d_{6}$ ) was performed on an AB Sciex API 3200 mass spectrometer [electrospray ionisation (ESI) in the positive ion mode] and the settings on the apparatus are summarised in a previously published method [31]. Furthermore, a stock solution of indinavir was prepared in DMSO at a concentration of $1 \mathrm{mg} / \mathrm{mL}$. Sprague-Dawley blank plasma samples were spiked with the stock solution to obtain standard 1 (STD 1) at a concentration of $2000 \mathrm{ng} / \mathrm{mL}$. Dilution of this solution with blank plasma resulted in STD $2(500 \mathrm{ng} / \mathrm{mL})$, STD 3 (125 ng/mL), STD 4 (32 ng/mL), STD 5 (8 ng/mL), and STD 6 (2 ng/ $\mathrm{mL})$. Quality control samples were also prepared in the same pool of rat plasma at $1600 \mathrm{ng} / \mathrm{mL}, 400 \mathrm{ng} / \mathrm{mL}, 50 \mathrm{ng} / \mathrm{mL}, 10 \mathrm{ng} / \mathrm{mL}$, and $2 \mathrm{ng} / \mathrm{mL}$. The calibration standards and quality control samples were briefly vortexed and aliquoted into labelled poly-

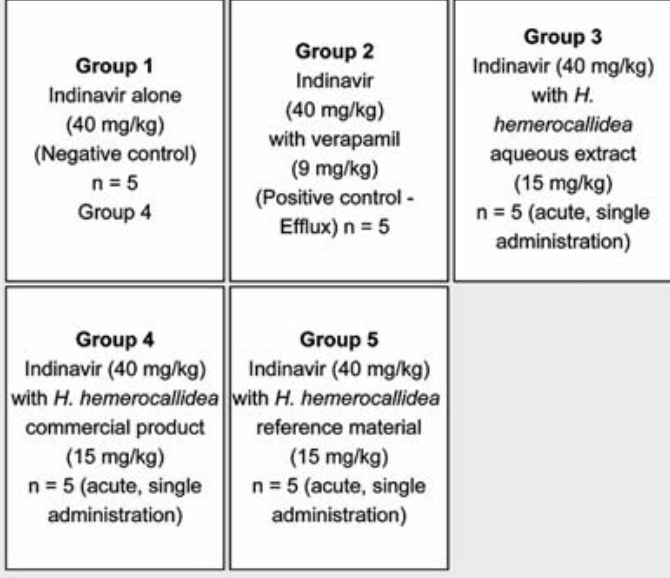

- Fig. 4 Layout of the in vivo pharmacokinetic study design in Sprague Dawley rats.

propylene tubes, which were stored at $-80^{\circ} \mathrm{C}$ until analysis with LC/MS/MS. Samples above the upper limit of quantification were diluted 4 times with blank plasma and reanalysed in a repeat batch [32]. The method was validated in terms of linearity, accuracy, and precision.

The extraction was done by adding $200 \mu \mathrm{L}$ of ice-cold $0.1 \%$ formic acid in methanol containing $20 \mathrm{ng} / \mathrm{mL}$ internal standard (indinavir-d6) to a $20-\mu \mathrm{L}$ sample of plasma, which was vortex mixed for $60 \mathrm{~s}$. This was followed by ultrasonication for $10 \mathrm{~min}$ and centrifugation at $10000 \mathrm{rpm}$ for $10 \mathrm{~min}$. Then, $180 \mu \mathrm{L}$ of the supernatant were transferred into clean culture tubes and evaporated to dryness under nitrogen gas at $40^{\circ} \mathrm{C}$. The residue was reconstituted with $100 \mu \mathrm{L}$ of $0.1 \%$ formic acid in water, and vortex mixed for $60 \mathrm{~s}$. The extracts were transferred into a 96-well plate for injection. A volume of $10 \mu \mathrm{L}$ of the reconstituted extract solutions was injected onto the column.

WinNonlin software (Pharsight Corporation) was used in order to construct the indinavir bioavailability profiles. Relevant pharmacokinetic parameters (i.e., $\mathrm{C}_{\max }$ and $\mathrm{AUC}_{0_{-\infty}}$ ) were obtained. The $F_{\text {rel }}$ of indinavir was calculated by using the following equation:

$F_{\text {rel }}=\frac{\left[\mathrm{AUC}_{0-\infty}\right]_{\mathrm{A}}}{\left[\mathrm{AUC}_{0-\infty}\right]_{\mathrm{B}}}$

Where $[A U C]_{A}$ represents the area under the curve for indinavir in the presence of the experimental material (i.e., each selected $H$. hemerocallidea material) and $[\mathrm{AUC}]_{\mathrm{B}}$ represents the area under the curve for indinavir alone.

\section{Statistical analysis}

Data analyses were performed with STATISTICA Ver 12. ANOVA's with Tukey's honest significant post hoc tests were performed, and statistically significant differences were accepted when $p<0.05$. All results were verified with nonparametric KruskallWallis and Dunn's post hoc tests. 


\section{Supporting information}

Indinavir mean plasma concentrations at each time point after oral administration to rats in the absence and presence of the selected $H$. hemerocallidea materials are available as Supporting Information.

\section{Acknowledgements}

The financial assistance of the Medical Research Council (MRC) of South Africa as well as the National Research Foundation (NRF; grant nr. 103479) of South Africa are acknowledged. Opinions expressed and conclusions arrived at are those of the authors and are not necessarily to be attributed to the MRC or NRF. Dr. Weiyang Chen (Tshwane University of Technology) is thanked for profiling the test materials of $\mathrm{H}$. hemerocallidea.

\section{Conflict of Interest}

The authors declare no conflict of interest.

\section{References}

[1] Owira PM, Ojewole JA. 'African Potato' (Hypoxis hemerocallidea corm): a plant-medicine for modern and 21st century diseases of mankind? a review. Phytother Res 2009; 23: 147-152

[2] Brijlal N, Khoza N, Mbonane N, Meyiwa S, Moodley S, Parbhoo T, Pillay E, Lubbe $\mathrm{M}$, Bodenstein J. The attitudes and knowledge of pharmacists towards the use of herbal medicine. S Afr Pharm J 2011; 78: 35-37

[3] Oga EF, Sekine S, Shitara Y, Horie T. Pharmacokinetic herb-drug interactions: insight into mechanisms and consequences. Eur J Drug Metab Pharmacokinet 2016; 41: 93-108

[4] Sibanda M, Naidoo P, Nlooto M. African traditional medicine use amongst people living with HIV/AIDS in sub-Saharan Africa in the era of antiretroviral therapy. Int J Pub Health Safe 2016; 1: 1-4

[5] Oyebode O, Kandala NB, Chilton PJ, Lilford RJ. Use of traditional medicine in middle-income countries: a WHO-SAGE study. Health Policy Plan 2016; 31: 984-991

[6] Abdullahi AA. Trends and challenges of traditional medicine in Africa. Afr J Tradit Complement Altern Med 2011; 8: 115-123

[7] Wiersum KF, Dold AP, Husselman M, Cocks M. Cultivation of medicinal Plants as a Tool for Biodiversity Conservation and Poverty Alleviation in the Amatola Region, South Africa. In: Bogers RJ, Craker LE, Lange D, eds. Medicinal and aromatic Plants. Wageningen: Springer; 2006: 43-57

[8] Sukati NA, Mndebele SC, Makoa ET, Ramukumba TS, Makoae LN, Seboni NM, Human S, Holzemer WL. HIV/AIDS symptom management in Southern Africa. J Pain Sym Man 2016; 29: 185-192

[9] Sibanda M, Nlooto M, Naidoo P. Concurrent use of antiretroviral and African traditional medicines amongst people living with HIV/AIDS (PLWA) in the eThekwini Metropolitan area of KwaZulu Natal. Afri Health Sci 2016; 16: 1118-1130

[10] Cohen K, Andrews S, Maartens G. Antiretroviral therapy and drug interactions. S Afr Med J 2001; 91: 816-819

[11] Yang XX, Hu ZP, Duan W, Zhu YZ, Zhou SF. Drug-herb interactions: eliminating toxicity with hard drug design. Curr Pharm Design 2006; 12: 4649-4664

[12] Tarirai C, Viljoen AM, Hamman JH. Herb-drug pharmacokinetic interactions reviewed. Exp Opin Drug Metab Toxicol 2010; 6: 1515-1538
[13] Lam YWF, Ernst E. Botanical Products - Drug Interactions: Focus on Garlic, Ginkgo and Ginseng. In: Lam YWF, Huang SM, Hall SD, eds. Herbal Supplements - Drug Interactions. London: Taylor \& Francis; 2006: 26

[14] Cordier W, Steenkamp V. Drug interactions in African herbal remedies. Drug Metab Drug Interact 2011; 26: 53-63

[15] Pal D, Mitra AK. MDR- and CYP3A4-mediated drug-herbal interactions. Life Sci 2006; 78: 2131-2145

[16] Liu C, Yi X, Si D, Xiao X, He X, Li Y. Herb-drug interactions involving drug metabolizing enzymes and transporters. Curr Drug Metab 2011; 12: 835-849

[17] Van Wyk BE, Van Outshoorn B, Gericke N. Medicinal Plants of South Africa, 2nd edition. Pretoria: Briza Publications; 2002: 336

[18] Singh Y. Hypoxis: yellow stars of horticulture, folk remedies and conventional medicine. Veld Flora 1999; 85: 123-125

[19] Drewes SE, Elliot E, Khan F, Dhlamini JTB, Gcumisa MSS. Hypoxis hemerocallidea - not merely a cure for benign prostate hyperplasia. J Ethnopharmacol 2008; 119: 593-598

[20] Nair VDP, Foster BC, Arnason JT, Mills E], Kanfer I. In vitro evaluation of human CYP450 and P-glycoprotein-mediated metabolism of some phytochemicals in extracts and formulations of African potato. Phytomed 2006; 14: 498-507

[21] Mogatle S, Skinner M, Mills E, Kanfer I. Effect of African potato (Hypoxis hemerocallidea) on the pharmacokinetics of efavirenz. S Afr Med J 2008: 98: 945-949

[22] Darby RAJ, Callaghan R, McMahon RM. P-glycoprotein inhibition: the past, the present and the future. Curr Drug Metab 2011; 12: 722-731

[23] Benet LZ, Cummins CL. The drug efflux-metabolism alliance: biochemical aspects. Adv Drug Del Rev 2001; 50: S3-S11

[24] Drewes SE, Khan F. The African potato (Hypoxis hemerocallidea): a chemical-historical perspective. S Afr J Sci 2004; 100: 425-430

[25] Hochman JH, Chiba M, Nishime J, Yamazaki M, Lin JH. Influence of P-glycoprotein on the transport and metabolism of indinavir in Caco-2 cells expressing cytochrome P-450 3A4. J Pharmacol Exp Ther 2001; 298: 310-318

[26] Mills E, Foster BC, Van Heeswicjk R. Impact of African herbal medicines on antiretroviral metabolism. AIDS 2005; 19: 95-97

[27] Zuber R, Anzenbacherová E, Anzenbacher P. Cytochromes P450 and experimental models of drug metabolism. J Cell Mol Med 2002; 6: 189198

[28] Alqahtani S, Mohamed LA, Kaddoumi A. Experimental models for predicting drug absorption and metabolism. Expert Opin Drug Metab Toxicol 2013; 9: 1241-1254

[29] Calitz C, Gouws C, Viljoen J, Steenekamp J, Wiesner L, Abay E, Hamman J. Herb-drug pharmacokinetic interactions: transport and metabolism of indinavir in the presence of selected herbal products. Molecules 2015; 20: $22113-22127$

[30] Fasinu PS, Gutmann H, Schiller H, Bouic P], Rosenkranz B. The potential of Hypoxis hemerocallidea for herb-drug interaction. Pharm Biol 2013; 51 : 1499-1507

[31] Choi DH, Li C, Cho JS. Effects of simvastatin on the pharmacokinetics of verapamil and its main metabolite, norverapamil, in rats. Eur J Drug Metab Pharmacokinet 2009; 34: 63-168

[32] Wallis L, Malan M, Gouws C, Steyn D, Ellis S, Abay E, Wiesner L, Otto DP, Hamman J. Evaluation of isolated fractions of Aloe vera gel materials on indinavir pharmacokinetics: in vitro and in vivo studies. Curr Drug Deliv 2016; 13: 471-480 